\title{
Change in tactual form discrimination error scores as a function of vibratory stimulation '
}

GLEN M. VAUGHT

ALBION COLLEGE

Twenty females, who had proviously participated in a similar experiment some six to eight months prior to the present study, were recalled in order to test the stability of the present tactual form discrimination task and to determine the effects of brief applications of vibration in tactful form discrimination. The discrimination measure was found to be remarkably stable and vibration reduced the number of errors made in form discrimination.

Gibson (1966) has stressed the redundancy of information within a given nervous system brought about by the inherent structure of an organism's perceptual systems. In addition to structural limitations, there are other complexities involved in the organism's general adaptation to its surround. Thus it is often difficult to separate one system from another. For example, sighted people rely more heavily on vision than on the haptic system; however, this does not preclude the vast amount of information gained through the haptic system. It does, however, highlight the need to know more about such relationships. The overall complexity of this area of research together with the Iack of an extensive literature provide a wealth of unanswered questions and some formidable problems as well.

Previous work by the author (Vaught \& Augustson, 1967a, b; Vaught \& Ellinger, 1966) has focused on demonstrating that the visual perceptual system, as reflected in rod and frame test (RFT) scores, is related to tactual form discrimination in predictable ways. Moreover, the above studies have shown that individuals make significantly more discrimination errors in passive touch than in active touch. It is apparent that the act of touching provides the $S$ with more cues from which to correctly identify the presented form than does passive touch.

In view of the above findings, the present study sought to test the stability of the form discrimination task by recalling a number of Ss who had previously participated in a similar experiment some six to eight months prior to the present study. In addition, this study investigated the effects of vibration in both active and passive tactual form discrimination. Since vibration is thought to be a mechanical event that stimulates the skin and presumably the joints and muscles as well, it was hypothesized that vibration would reduce the number of errors in form discrimination.

\section{Method}

The Ss were 20 female introductory psychology students who had participated in a similar study some six to eight months prior to this experiment. Ten of the Ss were field-dependent (FI), and ten were field-dependent (FD) as determined by RFT performance in the previous study. It should be noted that field-dependence is not of central importance to the present study; rather, it is included in this study because of prior group placement.

The forms and the $\mathrm{E}$ were the same as those used by the author in previous work (Vaught \& Augustson, $1967 \mathrm{a}, \mathrm{b})$. The procedure differed from past studies in that this study included brief applications of mechanical vibration to the shoulder musculature of each S. Vibration was provided by a 60 cycle, Chic massage vibrator.

All Ss were given 48 trials in form discrimination, 24 active and 24 passive. The 24 trials were further divided into two blocks of 12 trials for each of the two touch conditions. For example, each $S$ received 24 trials under active touch, 12 of which included $20 \mathrm{sec}$ vibration randomly applied to the shoulder musculature, and 12 trials without vibration. The same was true for passive touch trials. A $2 \mathrm{~min}$ rest period was used between each block of 12 trials. As in the earlier studies, precautions were taken to balance learning by the Ss and to control for possible sequential effects. For this reason, the order of stimulus presentation was randomized within Ss and between Ss as well.

\section{Results and Discussion}

Table 1 shows the mean discrimination error scores for all groups. The means in parentheses refer to error scores for these same Ss six to eight months prior to this experiment. As can be seen, there was little or no difference between the present mean values and the previous means for these same Ss. It would seem that this is a very stable measure of form discrimination, and that practice effects, if they occur, dissipate as a function of time.

$T$ tests for correlated samples were used to test the significance of the differences between the means in Table 1. Within the FD group, vibration signif-

Table 1. Mean Discrimination Error Scores for all Groups

\begin{tabular}{ccccc} 
& \multicolumn{2}{c}{$\begin{array}{c}\text { Active Touch } \\
\text { Vibration }\end{array}$} & No Vibration & \multicolumn{2}{c}{$\begin{array}{c}\text { Passive Touch } \\
\text { Vibration }\end{array}$} & $\begin{array}{c}\text { No Vibration } \\
\text { F1 }\end{array}$ & 1.30 & 1.20 & 3.90 & 8.00 \\
& & $(1.50)$ & & $(7.20)$ \\
FD & .10 & .80 & 2.90 & 5.80 \\
& & $(1.10)$ & & $(5.30)$ \\
\hline
\end{tabular}

Means in parenthesis are for the sume ss sir to ciaht monthi prior to this study. 
icantly reduced the number of errors in passive touch from a mean of 5.80 to a mean of $2.90(t=4.14$, $\mathrm{df}=9, \mathrm{p}<.01$ ). Similarly, vibration brought about a reduction in discrimination errors for passive touch within the FI group. The difference between the means of 8.00 and 3.90 was highly significant $(t=6.40$, df $=9, p<.001)$. The remaining significant difference occurred between the FI active touch with vibration and the FD active touch with vibration $(t=2.75$, df $=9, p<.05$ ). The FI Ss made significantly more errors in the discrimination task than did the FD Ss. This latter finding supports previous work by the author in which vibration was not used (Vaught \& Augustson, 1967b).

The results of the present study have shown that vibration applied to the shoulder musculature in brief applications does, in fact, reduce errors in tactual form discrimination. Furthermore, there can be little doubt concerning the stability of the performance measure used in this study.

The question of why vibration altered form discrimination scores is open to speculation. The questions of what are the stimulus components of vibratory stimulation and how these stimuli become registered in individual awareness remain largely unanswered at this time. Geldard (1953) concluded that "the vibratory pattern is in fact pressure in movement" and ruled out the notion of a separate vibratory sense ( $p$. 184-185). Gibson (1962) placed vibration with stretching, kneading, and pinching under the heading of mechanical events that stimulate the skin without displacement (p. 480). It would seem reasonable to assume that vibration directly affects the haptic perceptual system and the net result appears to be one of facilitation in form discrimination.

The overall consequences of mechanical vibration as reflected in various performance measures would, no doubt, vary with the kind of stimulation used, body-part application, the duration and intensity of the stimulus, and a number of additional factors. Hostetler (personal communication) in a recent study found an enhancement of critical flicker fusion when accompanied by vibratory stimulation applied to the S's hand. He reasoned that "the feature of intermittency...vibration shows with a flickering light... affects in some way the pattern(s) of neural firing responsible for the efficiency with which the visual system processes afferent information." It seems plausible that the haptic perceptual system shares a similar kind of relationship with vibration.

\section{References}

GELDARD, F. A. The human senses. New York: John Wiley \& Sons, Inc., 1953.

GIBSON, J. J. The senses considered as perceptual systems. Boston: Houghton Mifflin Co., 1966.

GIBSON, J. J. Observations on active touch. Psychol. Rev., 1962, 69, 477-490.

HOSTETLER, J. P. Personal communication. Albion College, Albion, Michigan.

VAUGHT, G. M., \& AUGUSTSON, BARBARA. Field-dependence and form discrimination in females. Psychon. Sci. 1967a, 7, 333-334.

VAUGHT, G. M., \& AUGUSTSON, BARBARA. Field-dependence and form discrimination in males. Psychon. Sci., 1967b, 8, 233-234.

VAUGHT, G. M., \& ELLINGER, J. Field-dependence and form discrimination. Psychon. Sci, 1966, 6, 357-358.

Note

1. Thanks goes to Barbara Augustson for running the Ss and to Dr. John P. Hostetler for telling me of his recent research. 